\title{
Differential expression of filamin B splice variants in giant cell tumor cells
}

\author{
JOSEPH CHI-CHING TSUI ${ }^{*}$, CAROL PO-YING LAU $^{1,2^{*}}$, ALEX CHUN CHEUNG ${ }^{2}$, KWOK-CHUEN WONG ${ }^{1}$, \\ LIN HUANG $^{3}$, STEPHEN KWOK-WING TSUI ${ }^{2}$ and SHEKHAR MADHUKAR KUMTA ${ }^{1}$ \\ ${ }^{1}$ Department of Orthopaedics and Traumatology, ${ }^{2}$ School of Biomedical Sciences, ${ }^{3}$ Department of Surgery, \\ The Chinese University of Hong Kong, Shatin, Hong Kong, SAR, P.R. China
}

Received June 15, 2016; Accepted October 18, 2016

DOI: $10.3892 /$ or.2016.5197

\begin{abstract}
Giant cell tumor of bone(GCT) is the most commonly reported non-malignant bone tumor in Hong Kong. This kind of tumor usually affects people aged 20-40 years. Also, it is well known for recurrence locally, especially when the tumor cannot be removed completely. Filamins are actin-binding proteins which contain three family members, filamin A, B and $\mathrm{C}$. They are the products of three different genes, FLNA, FLNB and FLNC, which can generate various transcript variants in different cell types. In this study, we focused on the effects of FLNBv2 and FLNBv4 toward GCT cells. The only difference between FLNBv2 and FLNBv4 is that FLNBv4 does not contain hinge 1 region. We found that the relative abundance of FLNBv4 varies among different GCT cell lines while the expression level of FLNBv4 in normal osteoblasts was only marginally detectable. In the functional aspect, overexpression of FLNBv4 led to upregulation of RANKL, OCN, OPG and RUNX2, which are closely related to GCT cell survival and differentiation. Moreover, FLNBv4 can have a negative effect on cell viability of GCT cells when compare with FLNBv2. In conclusion, splicing variants of FLNB are differentially expressed in GCT cells and may play a role in the proliferation and differentiation of tumor cells.
\end{abstract}

\section{Introduction}

Giant cell tumor of bone (GCT) is the most commonly reported non-malignant bone tumor in Hong Kong (1). This

Correspondence to: Professor Shekhar Madhukar Kumta, Department of Orthopaedics and Traumatology, The Chinese University of Hong Kong, Shatin, Hong Kong, SAR, P.R. China E-mail:kumta@cuhk.edu.hk

Professor Stephen Kwok-Wing Tsui, School of Biomedical Sciences, The Chinese University of Hong Kong, Shatin, Hong Kong, SAR, P.R. China

E-mail:kwtsui@cuhk.edu.hk

*Contributed equally

Key words: filamin B, giant cell tumor of bone, splicing variants kind of tumor usually affects people aged 20-40 years (2). The tumor leads to bone destruction near the major skeletal joints and surgery is usually needed in order to remove the tumor and save the joint. Moreover, GCT is well known for recurrence locally, especially when the tumor cannot be removed completely. GCT is comprised of 3 histological different cell types; the multinucleated osteoclast-like giant cells, spindle-shaped stromal-like cells and the monocytic round-shaped macrophage-like cells (3-5). The stromal cells of GCT are the unique primary neoplastic cells as well as the only proliferating cell component in the cell culture of tumor cells (6). It is well known that macrophage-like GCT cells are osteoclast precursors. GCT stromal cells (GCTSC) can express osteoblastic lineage markers such as bone sialoprotein, collagen type I and osteonectin proteins.

Filamins, which are actin-binding proteins, contain three family members, filamin A, B and C. They are the products of three different genes, FLNA, FLNB, and FLNC, which can generate various transcript variants in different cell types (7). FLNA is predominantly expressed in the brain and blood vessels while FLNB and FLNC can be found in bones and muscles, respectively (8). Filamins are vital to formation and maintenance of cell morphology, motility for responding to the external stimuli and differentiation. They are also able to interact with $>90$ binding partners which include ion channels, receptors, intracellular signaling molecules, transcription factors and other cytoskeleton proteins. Therefore, they are mediators of many cellular processes (9-11). Regarding the structure of filamin $\mathrm{B}$, it contains the $\mathrm{N}$-terminal actin-binding domain (ABD), which includes two calponin-homology domains ( $\mathrm{CH} 1$ and $\mathrm{CH} 2$ ), followed by 24 immunoglobulinlike repeats. Repeats $1-15$ represent the first rod domain and are interrupted by a hinge region (hinge 1), then repeats 16-23 form the second rod domain and interrupted by a second hinge region (hinge 2). Finally, the $\mathrm{C}$-terminal repeat 24 is the dimerization domain $(7,12,13)$. The hinge 1 region is related to filamin flexibility and some isoforms do not contain this region $(14,15)$.

In this study, we focus on two FLNB isoforms: FLNB variant2 (FLNBv2) and FLNB variant4 (FLNBv4). FLNBv2 is known as ABP-278 and FLNBv4 is known as ABP-276 when they were being discovered. FLNBv2 is the dominant isoform in prostate, uterus, small intestine, liver, lymph 
node, stomach, lung, thyroid and spleen, whereas, FLNBv4 is dominant in Daudi cells and spinal cord. The placenta, bone marrow and brain express both isoforms with comparable level (16). The only difference of FLNBv2 and FLNBv4 is that FLNBv4 does not contain hinge 1 region. In terms of their function, FLNBv4 accelerates mouse myoblasts differentiation into myotubes (17). This may be due to the different localization of FLNBv2 and FLNBv4 in the differentiating cells. Also, FLNBv2 and FLNBv4 have very different binding affinity towards integrins, which transduce signals through interactions of their cytoplasmic tails with cytoskeletal and signaling proteins (18). This difference may lead to the alteration of signal transduction in several signaling events critical for tumorigenesis (19).

We report on the differential expression of FLNB splicing variants in GCTSC. Moreover, the clinical and functional significance of the alteration was explored. We found that the relative abundance of FLNBv4 varies among different GCT cell lines while the expression level of FLNBv4 in normal osteoblast (OB) was only marginally detectable. This phenomenon could also be observed in liver cancer tissues and their adjacent normal counterparts. In the functional aspect, overexpression of FLNBv4 led to upregulation of RANKL, VEGFA and RUNX2, which are closely correlating with GCT formation and cancer cell survival. In terms of proliferation, overexpression of FLNBv2 increases cell viability and FLNBv4 decreased cell viability in some cell lines. In conclusion, FLNBv2 increase GCT cell proliferation and FLNBv4 is highly correlated with differentiation genes.

\section{Materials and methods}

Patients information. GCT specimens were collected from the patients who underwent surgical excision of the tumor at Prince of Wales Hospital. All protocols were approved by the local Institutional Ethics Committee. The information of patients involved in this study is listed in Table I.

Primary culture of GCT SC. Primary culture of GCT stromal cells was established as previously described (20). Briefly, freshly extracted tissues were minced with scissors in DMEM medium which contains 10\% FBS (both from Thermo Fisher Scientific, Waltham, MA, USA) and $100 \mathrm{U} / \mathrm{ml}$ penicillin (PSN). The cell suspension was transferred to culture flasks and cultured at $37^{\circ} \mathrm{C}$ in a humidified atmosphere of $5 \% \mathrm{CO}_{2}$ and 95\% air. Culture medium was changed every 2-3 days upon reaching confluence and the cells were sub-cultured. GCTSC in cultures obtained after the 5 th passage, representing the proliferating homogeneous tumor cell population, were used for the following assays.

Construction of FLNBv4 plasmid. The recombinant plasmid clone of FLNBv2 in pCR3.1(-) vector driven by CMV promoter was a gift from Philip B. Daniel (18). The DNA sequences of the clones were in concordant with the reference sequence (NCBI accession no. NM_001457.3). The cloning method and plasmid construction were previously described (18). The FLNBv4 specific DNA fragment was obtained from G33 cDNA by PCR amplification using FLNBv4 cloning primers described in Table II. The FLNBv4 specific DNA fragment
Table I. Characteristics of the 16 patients with GCT.

\begin{tabular}{lccll}
\hline Sample & Gender & Age & \multicolumn{1}{c}{ Tumor localization } & \multicolumn{1}{c}{ Stage } \\
\hline G25 & M & - & Left distal femur, GCT & Stage III \\
G27 & M & 24 & Right distal radius, GCT & Stage III \\
G28 & F & 26 & Right distal femur, GCT & Stage II \\
G33 & M & 31 & Left distal radius, GCT & Stage II \\
G34 & M & 47 & Right knee, GCT & Stage II \\
G35 & F & 34 & Left tibial, GCT & Stage II \\
G36 & F & 30 & Left calcaneum, GCT & Stage II \\
G41 & F & 33 & Right femoral neck, GCT & Stage II \\
G42 & F & 14 & Left tibia, GCT & Stage II \\
G44 & M & 35 & Left os calcis, GCT & Stage II \\
G47 & M & 30 & Left distal femur, GCT & Stage III \\
G51 & F & 36 & Left distal radius, GCT & Stage II \\
G52 & F & 40 & Tibia, GCT & Stage II \\
G53 & F & 39 & Tibia, GCT & Stage II \\
G59 & F & 39 & Proximal tibia, GCT & Stage III \\
G62 & F & 48 & Ischial bone (pelvis), GCT & Stage II \\
\hline
\end{tabular}

M, male; F, female; GCT, giant cell tumor of bone.

Table II. Primer sequences designed for cloning and real-time PCR amplification.

Primer sequences

$\begin{array}{ll}\begin{array}{l}\text { LNBv4 } \\ \text { cloning }\end{array} & \text { F: 5'-AGATTCCTCGCAGTCCC-3' } \\ \text { FLNBv4 } & \text { R: 5'-GCTGTTGATTTCTGGGATTTT-3' } \\ \text { cloning } & \\ \text { GAPDH } & \text { F: 5'-CGCCCCACTTGATTTTGGA-3' } \\ \text { GAPDH } & \text { R: 5'-TTGCCATCAATGACCCCTTCA-3' } \\ \text { FLNBv2 } & \text { F: 5'-GCCGAGGCCGATGTCATTGAGAA-3' } \\ \text { FLNBv2 } & \text { R: 5'-CGGCTGTGACTTCCCCATCTGTG-3' } \\ \text { FLNBv4 } & \text { F: 5'-GCCGAGGCCGATGTCATTGAGAA-3' } \\ \text { FLNBv4 } & \text { R: 5'-ACATAGGCCTCTTCGGTCACCATGA-3' } \\ \text { RANKL } & \text { F: 5'-AACAGGCCTTTCAAGGAGCTGTGC-3' } \\ \text { RANKL } & \text { R: 5'-AAGAGGACAGACTCACTTTATGGG-3' } \\ \text { OPG } & \text { F: 5'-CAAAGTAAACGCAGAGAGTGTAGA-3' } \\ \text { OPG } & \text { R: 5'-GAAGGTGAGGTTAGCATGTCC-3' } \\ \text { RUNX2 } & \text { F: 5'-GAGTCCTTCTGTGGCA-3' } \\ \text { RUNX2 } & \text { R: 5'-GGCCGTTAGGGTTTGA-3' } \\ \text { OCN } & \text { F: 5'-GCCTTTGTGTCCAAGC-3' } \\ \text { OCN } & \text { R: 5'-GGACCCCACATCCATAG-3' }\end{array}$

M, male; F, female.

was cloned into the FLNB variant 2 plasmid between $\mathrm{MfeI}$ and SacII (NEB, Hitchin, UK) sites. The DNA sequence of the recombinant plasmid was confirmed by Sanger sequencing and found to the same as the reported sequence of FLNBv4 (NCBI accession no. NM_001164319.1). 

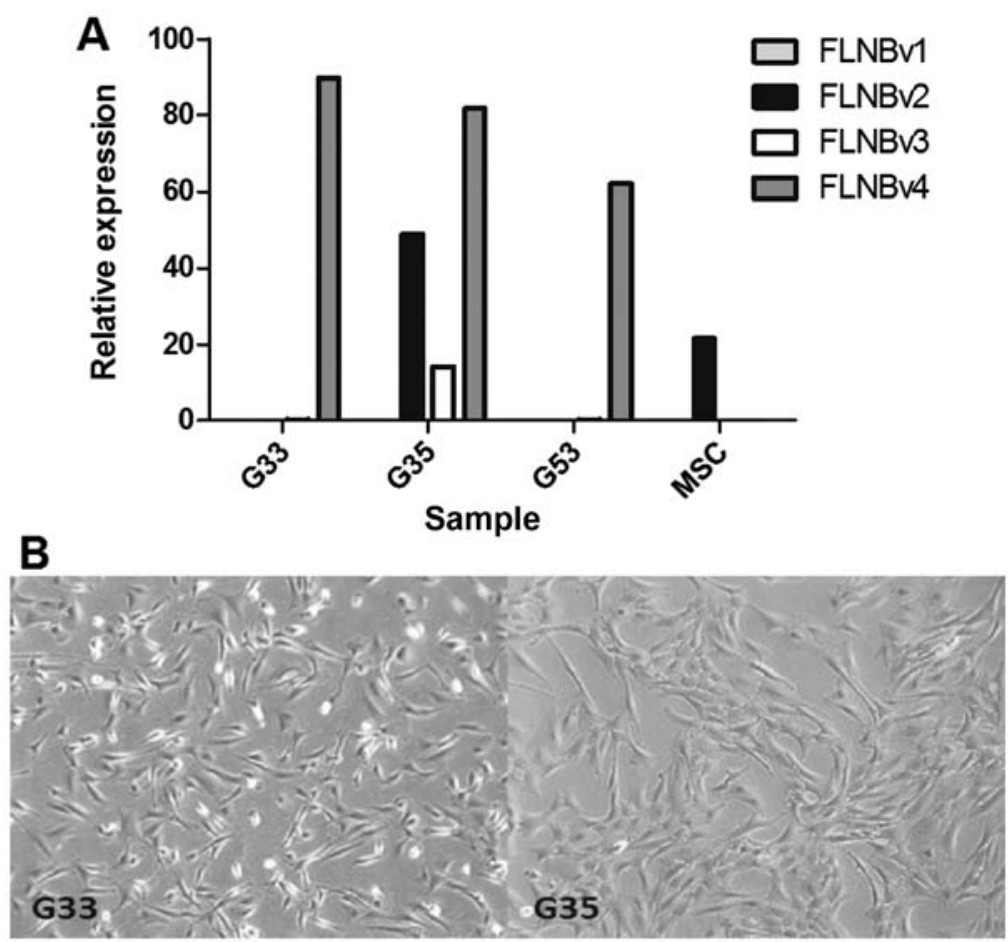

Figure 1. Expression level of filamin B (FLNB) transcript variants in giant cell tumor of bone stromal cells (GCTSC) by transcriptome analysis. (A) Expression level of different FLNB transcripts in three different GCT cell lines and MSC. (B) The morphology of GCT cell lines G33 and G35 by light microscopy.

RNA extraction and cDNA synthesis. Total RNA was extracted from GCT stromal cell lines using TRIzol reagent (Thermo Fisher Scientific) and the PureLink RNA Mini kit (Invitrogen, Carlsbad, CA, USA), following the manufacturer's instructions. Afterwards, $2.0 \mu \mathrm{g}$ of total RNA from each sample was subjected to cDNA synthesis using QuantiTect Reverse Transcription kit (Qiagen, Hilden, Germany).

Semi-quantitative PCR. Real-time PCR was performed on a ViiA 7 Real-Time PCR system using SYBR-Green master mix (both from Applied Biosystems, USA), according to the manufacturer's instructions. Fold-change was calculated using $\Delta \Delta \mathrm{Cq}$ method (21). Primer sequences are listed in Table II.

Cell counting kit-8 (CCK-8) assay. Cultured GCTSC were seeded on 96-well plates at a density of 7,000 cells/well overnight. Subsequently, the cells were transfected by FLNBv2 plasmid, FLNBv4 plasmid and empty vector using Lipofectamine 3000 (Thermo Fisher Scientific) respectively. After 2 and 4 days of transfection, CCK-8 assays were performed using the commercially available assay kit (Dojindo, Shanghai, China). The absorbance was measured at $450 \mathrm{~nm}$ using a microplate reader (Bio-Rad, Hercules, CA, USA).

\section{Results}

Expression level of FLNB transcript variants in GCTSC. To identify functionally important genes involved in the tumorigenesis of GCT, the transcriptome analysis of three GCT cell lines (G33, G35 and G53) and a control MSC cell line was performed. The results revealed that expression levels of FLNB variants in the three cell lines and MSC were significantly different (Fig. 1A). G33 and G53 are
FLNBv4 dominant while MSC are FLNBv2 dominant. It is interesting that $\mathrm{G} 35$ contains significant amounts of FLNBv2 and FLNBv3, although FLNBv4 is still the major transcript variant. In terms of cell morphology, we found that G33 is more polygonal and fan-shaped while G35 is more fibroblastlike (Fig. 1B). Moreover, according to our clinical record, the patient contributing the G35 cell line has had two recurrences. This may explain why the expression pattern of G35 is so different from the other two cell lines. To see whether this is a general phenomenon in GCT, real-time PCR was performed using 16 more GCT stromal cell lines (Fig. 2). Primers were designed specific to the sequence encoding the hinge 1 region and to the FLNBv4 transcript so as to differentiate FLNBv4 from other variants. Results show that the normal osteoblasts (OB) expressed a low level of FLNBv4. This is consistent with the observation of MSC results in the transcriptome analysis. In the GCT stromal cell lines, 14 have increased proportion of FLNBv4 relative to other variants. Of importance, eight of them have more FLNBv4 transcripts than the overall amount of other transcripts. Taken together, the amount of FLNBv4 transcripts is significantly elevated in GCT stromal cells.

Differential expression of FLNBv4 in liver cancer and adjacent normal tissues. To explore whether the increase in the transcript level of FLNBv4 could be observed in other cancer types, five liver cancer and adjacent normal tissue pairs were screened for the expression of FLNBv4 and other variants using real-time PCR (Fig. 3A). Statistical analysis revealed that the proportion of FLNBv4 transcripts relative to other variants was significantly increased by $\sim 5$-fold in liver cancer tissues (Fig. 3B). These results were consistent with our observation in GCT cell lines. 


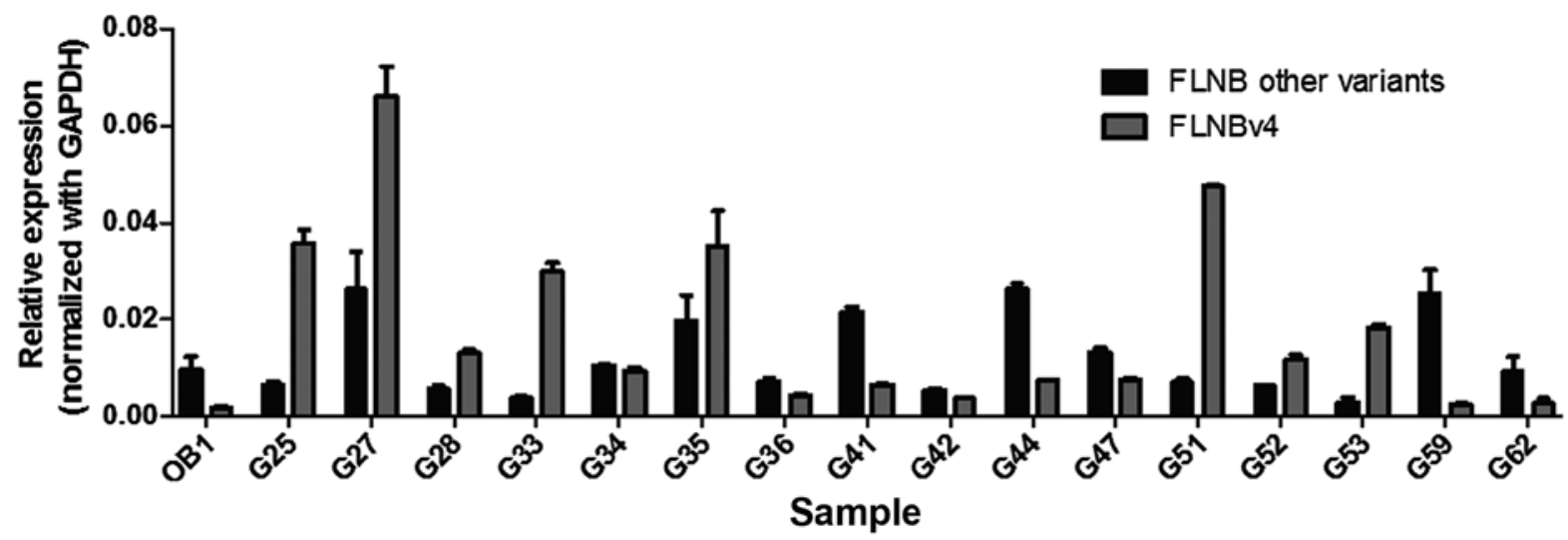

Figure 2. Expression level of filamin B (FLNB) transcript variants in giant cell tumor of bone stromal cells (GCTSC) by real-time PCR. Relative expression of FLNB variants determined by real-time PCR using 16 cDNA samples of GCT cell lines and one normal osteoblast cell line. GAPDH was used as a reference gene to normalize the expression level. Error bars represent standard deviations of triplicate assays.

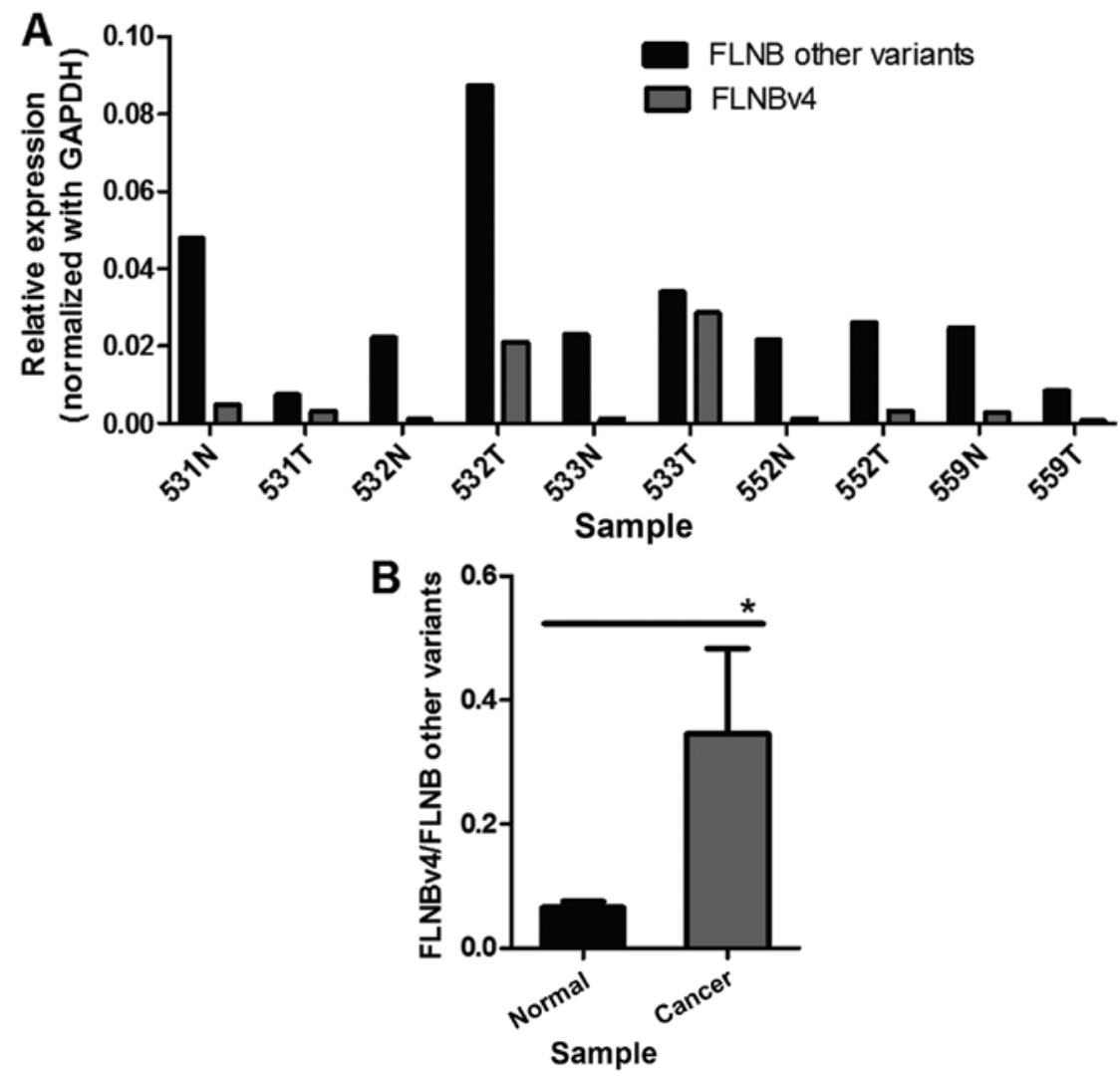

Figure 3. Differential expression of filamin B variant4 (FLNBv4) in liver cancer and adjacent normal tissues. (A) The relative expression levels of FLNBv4 and other FLNB variants were determined in five pairs of liver cancer tissues and their adjacent normal tissues by real-time PCR. GAPDH was used for normalization. T, tumor tissue; N, adjacent normal tissue. (B) The ratio of transcript level of FLNBv4 to other FLNB variants in liver cancer tissues and their adjacent normal tissues is shown. A significant difference in the ratio between liver cancer and normal tissues was found using paired t-test ("P $<0.05)$. Error bars represent standard deviations of five different samples.

Changes in gene expression triggered by FLNBv2 and FLNBV4. G33, G51 and G62 cells were transfected with FLNBv2, FLNBv4 and empty vector. After $72 \mathrm{~h}, \mathrm{RNA}$ was extracted and converted to cDNA. Real-time PCR was then used to examine the expression level of RANKL, OPG, OCN and RUNX2 in the transfected cells. We found that RANKL was significantly upregulated by 2-4-fold in FLNBv4 transfected GCT cell lines, whereas, FLNBv2 also induced a mild upregulation in G51 and G62 cells when compared with the empty vector transfected cells (Fig. 4A). Moreover, FLNBv4 could significantly and specifically upregulate OPG, OCN and RUNX2 by $>2$-fold in all three GCT cell lines (Fig. 4B-D).

Correlation of expression levels of FLNBv4 and RUNX2 in GCT cells. To study whether the endogenous expression level of FLNBv4 could be correlated with the expression of RANKL, OPG, OCN and RUNX2 in GCT cells, the expression of these four genes and the FLNBv4 was examined in 9 GCT 
A
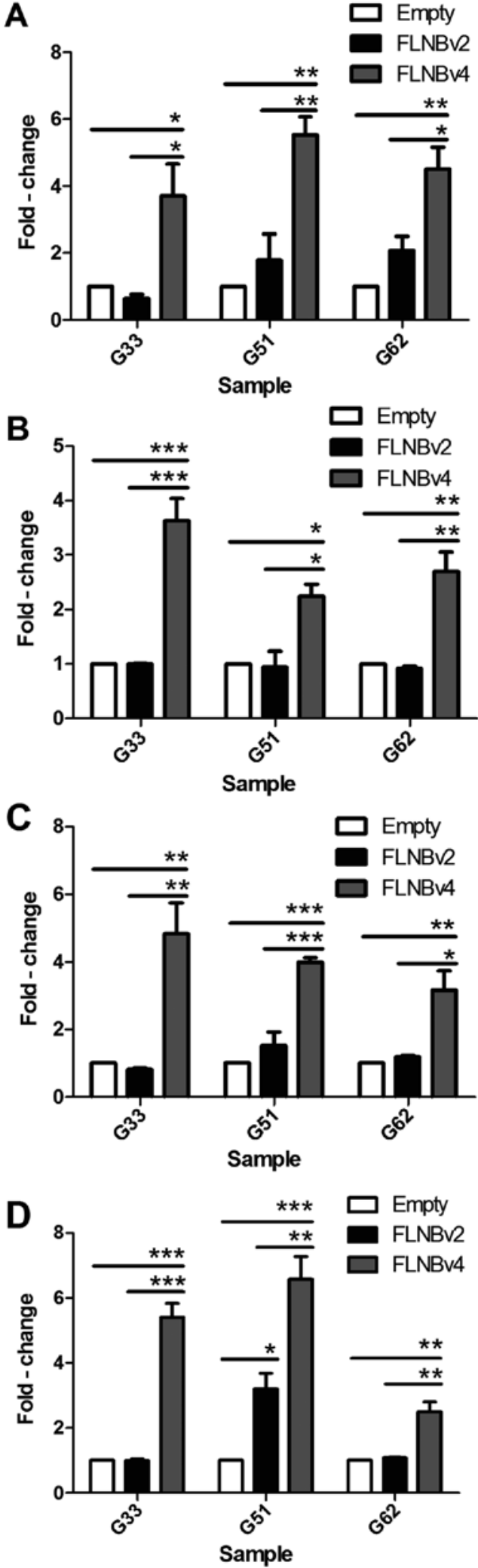

Figure 4. Changes in gene expression triggered by filamin B variant2(FLNBv2) and FLNBv4. Relative expression of four genes after the transfection of G33, G51 and G62 cells by FLNBv2, FLNBv4 and empty vector as revealed by real-time PCR. Error bars represent standard deviations of triplicate assays. (A) RANKL; (B) OCN; (C) OPG; (D) RUNX2 (n=3; $\mathrm{P}<0.05,{ }^{* *} \mathrm{P}<0.01$ and ${ }^{* * * *} \mathrm{P}<0.001$ using one way ANOVA when comparing the effects of each group).

cell lines by real-time PCR. A positive and high correlation $(\mathrm{P}=0.0174$ and $\mathrm{r}=0.8167)$ between FLNBv4 and RUNX2 was

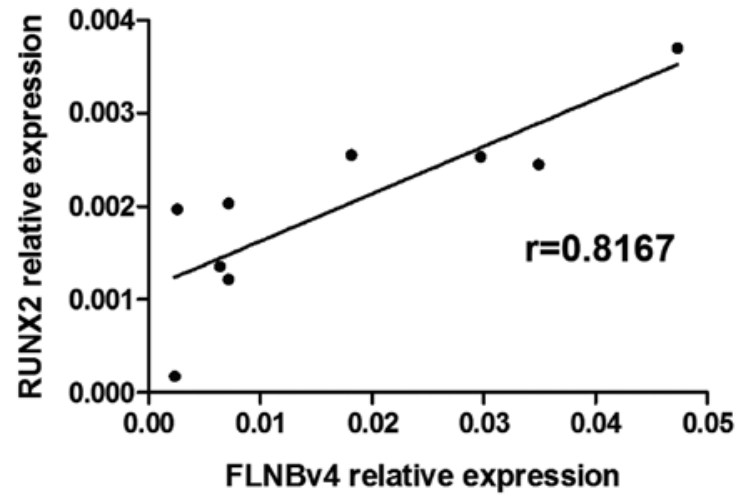

Figure 5. Correlation of expression levels of filamin B variant4 (FLNBv4) and RUNX2 in giant cell tumor (GCT) cells. Relative expression of FLNBv4 and RUNX2 determined by real-time PCR using 9 cDNA samples of GCT cell lines. GAPDH was used as a reference gene to normalize the expression level. A positive correlation between FLNBv4 and RUNX2 was identified $(\mathrm{P}=0.0174$ and $\mathrm{r}=0.8167)$.

identified (Fig. 5) while no significant correlation was found between FLNBv4 and the other three genes.

Effects of FLNBv2 and FLNBv4 on the proliferation of GCT cells. To investigate whether FLNBv2 and FLNBv4 could affect the proliferation of GCT cells, we transfected the G33, G51 and G62 cell lines with the recombinant plasmids expressing the FLNBv2 and FLNBv4 and the cell proliferation was subsequently determined by the CCK- 8 cell viability assay at 2 and 4 days post-transfection. In G33 cells, FLNBv2 transfected cells have a significantly higher cell viability when compared with FLNBv4 transfected cells in 2 and 4 days post-transfection (Fig. 6A). This phenomenon could be also observed in G62 cells in 2 days after post-transfection. However, the situation in G51 cells was totally different. The proliferation of FLNBv4 transfected cells was higher than that of FLNBv2 transfected cells, although the difference was not significant. It is notable that among the three cell lines G51 was the only cell line derived from a recurrent GCT.

\section{Discussion}

In our data, GCT cells express FLNBv4 which do not contain FLNB hinge 1 region. The expression level of FLNBv4 in normal osteoblast OB1 was undetectable. This phenomenon indicated that FLNBv4 is commonly found in GCT cells but not normal osteoblast cells. In our transcriptome analysis data, G33 and G53 are FLNBv4 dominant and G35 has a comparable amount of FLNBv2 and FLNBv4. The difference between G33, G53 and G35 may be explained by difference in morphology and tumor environment. Liver cancer tissues also have a higher FLNBv4 to other FLNB variants ratio compared with their own adjacent normal counterparts. Based on this observation, we suspected that high expression level of FLNBv4 is correlated with tumor formation.

In this study, we found that FLNBv4 can specifically upregulated RANKL in GCT cells. RANKL is well known to be highly expressed in GCT compared with normal osteoblasts or MSCs, and contributing for the accumulation of giant cells in GCT. Overexpression of RANKL in GCT 

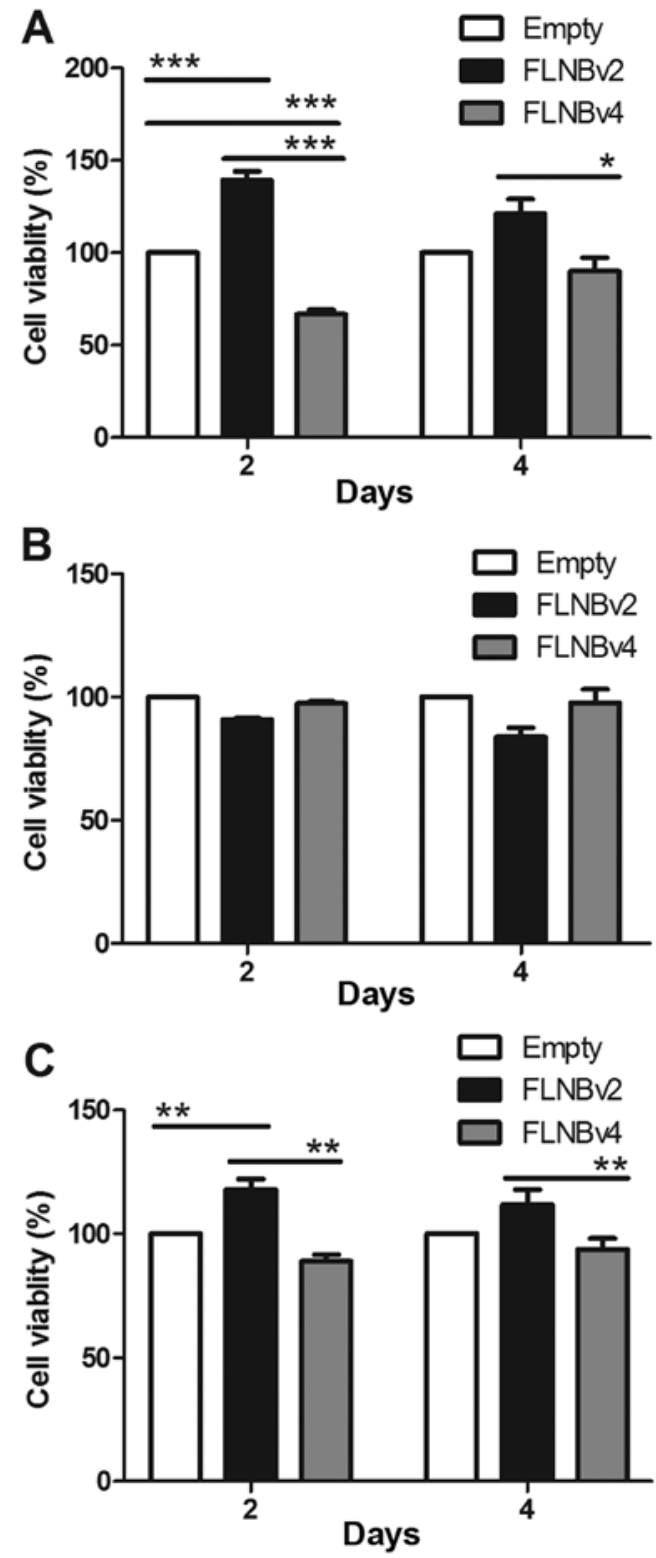

Figure 6. Effects of transfection of filamin B variant2 (FLNBv2) and FLNBv4 on the cell viability in giant cell tumor (GCT) cell lines. Cells were incubated for 2 and 4 days and the cell viability was then examined by cell counting kit-8 (CCK-8) assay. Cell viability in each experiment is normalized by cells transfected by empty plasmid. Error bars represent standard deviations of triplicate assays. (A) G33; (B) G51; (C) G62 ( $\mathrm{(} P<0.05,{ }^{* * *} \mathrm{P}<0.01$ and ${ }^{* * * *} \mathrm{P}<0.001$ using one way ANOVA).

microenvironment stimulates the secretion of tumor necrosis factor- $\alpha$ (TNF- $\alpha$ ) and interleukin- $1 \beta$ from giant cells, which in turn induces GCT stromal cell proliferation. RANKL is also an important signaling pathway which plays a vital role in osteoclastogenesis and bone resorption $(22,23)$. Bone resorption is necessary for the establishment and promotion of tumor metastasis in the bone $(24,25)$. In this pathway, RANKL can interact with its receptor RANK, which is on the surface of osteoclast precursors, to enhance activation, formation and survival of osteoclasts in normal stage or tumor stage (26). Therefore, the effect of FLNBv4 on RANKL can promote the tumor formation and bone resorption in GCT.

Moreover, our results suggest that FLNBv4-transfected cells have a higher level of RUNX2 when compared with FLNBv2-transfected cells. There is also a positive correlation between the expression level of FLNBv4 and RUNX2. RUNX2 is a regulatory gene of matrix metalloproteinase 13 (MMP13) and its encoded protein, Runx2, can activate the expression of MMP13 and hence promote the osteoclast differentiation and osteolysis (27). Moreover, Runx 2 contributes to the progression of cell cycle exit through binding with the hypophosphorylated form of $\mathrm{pRb}$. Our results suggest that FLNBv4 may promote GCT stromal cell differentiation through Runx2. It is notable that $\mathrm{OCN}$, which is a non-collagenous, vitamin K-dependent protein secreted in the late stage of osteoblasts differentiation (28), was also upregulated by FLNBv4, the expression level of OPG was increased by FLNBv4. OPG is an osteoclastogenesis inhibitory factor of the TNF family. It can inhibit the formation of osteoclast-like giant cell and prevent bone resorption (29). All the above results imply that the effect of FLNBv4 on Runx2, OCN and OPG is able to promote the differentiation and prevent bone resorption in GCT.

Taken together, FLNBv4 can produce opposite effects in GCT stromal cells through the transcriptional regulation of different genes. The balance between the promotion of proliferation and differentiation therefore determines the overall effect of FLNBv4. This is consistent with the fact that the expression level of FLNBv4 is highly variable in different GCT stromal cell lines. In addition, FLNBv4 can only inhibit the proliferation of two out of the three cell lines tested. The exact role of this splicing variant may depend on the genetic background and microenvironment of GCT stromal cells.

\section{Acknowledgements}

This study is supported by the Health and Medical Research Fund from the Food and Health Bureau, Hong Kong Special Administrative Region (reference no. 14130312).

\section{References}

1. Yip KM, Leung PC and Kumta SM: Giant cell tumor of bone. Clin Orthop Relat Res 323: 60-64, 1996.

2. Leung KH, Lam AY, Ho KW and Shek TW: Giant cell tumor of the humeral head treated by denosumab: Implication to shoulder surgeons. Int J Shoulder Surg 9: 135-138, 2015.

3. Zheng MH, Robbins P, Xu J, Huang L, Wood D and Papadimitriou J: The histogenesis of giant cell tumour of bone: a model of interaction between neoplastic cells and osteoclasts. Histol Histopathol 16: 297-307, 2001.

4. Sobti A, Agrawal P, Agarwala S and Agarwal M: Giant cell tumor of bone - An overview. Arch Bone Jt Surg 4: 2-9, 2016.

5. James IE, Walsh S, Dodds RA and Gowen M: Production and characterization of osteoclast-selective monoclonal antibodies that distinguish between multinucleated cells derived from different human tissues. J Histochem Cytochem 39: 905-914, 1991.

6. Huang L, Teng XY, Cheng YY, Lee KM and Kumta SM: Expression of preosteoblast markers and Cbfa-1 and Osterix gene transcripts in stromal tumour cells of giant cell tumour of bone. Bone 34: 393-401, 2004.

7. Razinia Z, Mäkelä T, Ylänne J and Calderwood DA: Filamins in mechanosensing and signaling. Annu Rev Biophys 41: 227-246, 2012.

8. Jeon GW, Lee MN, Jung JM, Hong SY, Kim YN, Sin JB and Ki CS: Identification of a de novo heterozygous missense FLNB mutation in lethal atelosteogenesis type I by exome sequencing. Ann Lab Med 34: 134-138, 2014.

9. Nakamura F, Stossel TP and Hartwig JH: The filamins: Organizers of cell structure and function. Cell Adhes Migr 5: 160-169, 2011. 
10. Popowicz GM, Schleicher M, Noegel AA and Holak TA Filamins: Promiscuous organizers of the cytoskeleton. Trends Biochem Sci 31: 411-419, 2006.

11. Stossel TP: Filamins and the potential of complexity. Cell Cycle 9: 1463, 2010.

12. Gorlin JB, Yamin R, Egan S, Stewart M, Stossel TP, Kwiatkowski DJ and Hartwig JH: Human endothelial actin-binding protein (ABP-280, nonmuscle filamin): A molecular leaf spring. J Cell Biol 111: 1089-1105, 1990.

13. Pudas R, Kiema TR, Butler PJ, Stewart M and Ylänne J: Structural basis for vertebrate filamin dimerization. Structure 13: 111-119, 2005.

14. Sawyer GM and Sutherland-Smith AJ: Crystal structure of the filamin N-terminal region reveals a hinge between the actin binding and first repeat domains. J Mol Biol 424: 240-247, 2012

15. Nakamura F, Osborn TM, Hartemink CA, Hartwig JH and Stossel TP: Structural basis of filamin A functions. J Cell Biol 179: 1011-1025, 2007.

16. Xu W, Xie Z, Chung DW and Davie EW: A novel human actin-binding protein homologue that binds to platelet glycoprotein Ibalpha. Blood 92: 1268-1276, 1998.

17. Dalkilic I, Schienda J, Thompson TG and Kunkel LM: Loss of FilaminC (FLNc) results in severe defects in myogenesis and myotube structure. Mol Cell Biol 26: 6522-6534, 2006.

18. van der Flier A, Kuikman I, Kramer D, Geerts D, Kreft M, Takafuta T, Shapiro SS and Sonnenberg A: Different splice variants of filamin-B affect myogenesis, subcellular distribution, and determine binding to integrin [beta] subunits. J Cell Biol 156 : 361-376, 2002

19. Giancotti FG and Ruoslahti E: Integrin signaling. Science 285: 1028-1032, 1999

20. Lau CP, Ng PK, Li MS, Tsui SK, Huang L and Kumta SM: p63 regulates cell proliferation and cell cycle progression associated genes in stromal cells of giant cell tumor of the bone. Int $\mathrm{J}$ Oncol 42: 437-443, 2013
21. Livak KJ and Schmittgen TD: Analysis of relative gene expression data using real-time quantitative PCR and the $2^{-\Delta \Delta C T}$ method. Methods 25: 402-408, 2001.

22. Wu PF, Tang JY and Li KH: RANK pathway in giant cell tumor of bone: Pathogenesis and therapeutic aspects. Tumour Biol 36 495-501, 2015.

23. Wang T, Yin H, Wang J, Li Z, Wei H, Liu Z, Wu Z, Yan W, Liu T, Song D, et al: MicroRNA-106b inhibits osteoclastogenesis and osteolysis by targeting RANKL in giant cell tumor of bone. Oncotarget 6: 18980-18996, 2015.

24. Lau CP, Huang L, Tsui SK, Ng PK, Leung PY and Kumta SM: Pamidronate, farnesyl transferase, and geranylgeranyl transferase-I inhibitors affects cell proliferation, apoptosis, and OPG/RANKL mRNA expression in stromal cells of giant cell tumor of bone. J Orthop Res 29: 403-413, 2011.

25. Huang L, Cheng YY, Chow LT, Zheng MH and Kumta SM: Tumour cells produce receptor activator of NF-kappaB ligand (RANKL) in skeletal metastases. J Clin Pathol 55: 877-878, 2002.

26. Dong SS, Liu XG, Chen Y, Guo Y, Wang L, Zhao J, Xiong DH, $\mathrm{Xu} \mathrm{XH}$, Recker RR and Deng HW: Association analyses of RANKL/RANK/OPG gene polymorphisms with femoral neck compression strength index variation in Caucasians. Calcif Tissue Int 85: 104-112, 2009

27. Huang Q, Jiang Z, Meng T, Yin H, Wang J, Wan W, Cheng M, Yan W, Liu T, Song D, et al: MiR-30a inhibits osteolysis by targeting RunX2 in giant cell tumor of bone. Biochem Biophys Res Commun 453: 160-165, 2014.

28. Neve A, Corrado A and Cantatore FP: Osteocalcin: Skeletal and extra-skeletal effects. J Cell Physiol 228: 1149-1153, 2013.

29. Huang L, Xu J, Wood DJ and Zheng MH: Gene expression of osteoprotegerin ligand, osteoprotegerin, and receptor activator of NF-kappaB in giant cell tumor of bone: Possible involvement in tumor cell-induced osteoclast-like cell formation. Am J Pathol 156: 761-767, 2000. 